\title{
Congenital hypothyroidism, spiky hair, and cleft palate
}

\author{
J S BAMFORTH* , I A HUGHES $\dagger$, J H LAZARUS $\ddagger$, C M WEAVER $\dagger$, AND \\ P S HARPER* \\ ${ }^{*}$ Institute of Medical Genetics, and Departments of + Child Health and $¥$ Medicine, University of Wales \\ College of Medicine, Heath Park, Cardiff CF4 $4 X N$.
}

SUMmary Two brothers are described with athyroidal hypothyroidism, spiky hair, choanal atresia, cleft palate, and bifid epiglottis. Polyhydramnios was present in the third trimester of each pregnancy. These abnormalities appear to represent a new syndrome.

\section{Case reports}

The brothers are the offspring of healthy, nonconsanguineous, Caucasian parents. The ages of the mother and father were 23 and 27 years respectively at the birth of their first infant. The family history is unremarkable.

The first pregnancy proceeded until the third trimester when mild polyhydramnios was noted. Labour started spontaneously at 39 weeks' gestation and the infant was delivered by emergency caesarean section for fetal distress. Apgar scores were 7 and 9 at one and five minutes after delivery.

The infant suffered repeated episodes of apparent airway obstruction. Shortly after birth, examination of the airways showed a palatal cleft extending to the posterior one-third of the hard palate. At the posterior edge of the defect the oropharynx had fused with the roof of the nasopharynx, completely obliterating the choanae. The epiglottis was hypoplastic and bifid but the larynx was of normal diameter. The jaw was retrognathic. Scalp hair was sparse and spiky. Neuromuscular tone was increased.

The neonatal period was complicated by repeated apnoeic episodes which frequently followed feeds and were associated with opacities on the chest radiograph. Aspiration pneumonitis was considered

§Present address: Clinical Genetics Unit, University of British Columbia, 4490 Oak Street, Vancouver, BC V6H 3V5, Canada.

Received for publication 13 August 1986.

Revised version accepted for publication 8 March 1988. to be the most likely cause, although this was not substantiated radiologically.

The choanae were repaired at six weeks of age and the cleft palate at 18 months; both operations were uneventful.

The infant had been transferred from an area whicis was not served by the regional congenital hypothyroid screening programme at the time of birth. When this was appreciated at three months of age, screening was performed. The initial result showed a high TSH. A further serum sample was taken; the serum TSH was $181 \mathrm{IU} / 1$ (normal <5) and the free T4 concentration was $5 \mathrm{pmol} / \mathrm{l}$ (normal 60 to 150 ). No thyroid uptake was noted on $I^{123}$ scan.

At the age of three years the infant was functioning developmentally at a two year level. Delay was most marked in the cognitive and language fields. Physical growth has been normal. Hair growth has been slow and it was not until 18 months of age that sufficient hair had grown to cover the scalp. He had only required one hair cut in his life. Nail growth and teeth are normal. Sweating is normal and dermal ridge sweat pore count is normal. ${ }^{1}$

The second infant was born two years after the first infant. Polyhydramnios was again present in the third trimester and emergency caesarean section was required for fetal distress. The Apgar scores were 6 and 9 at one and five minutes. Obstructed respiration was immediately observed and examination of the upper airways showed choanal atresia, cleft palate, bifid epiglottis, and micrognathia. The hair was sparse and spiky. The similarity in the physical features of the second and first infant prompted immediate examination of thyroid function. The serum TSH was $205 \mathrm{IU} / \mathrm{l}$ and the free T4 was 4 $\mathrm{pmol} / \mathrm{l}$. No $\mathrm{I}^{123}$ uptake was detected on isotope scanning. Thyroid replacement was started immediately. The choanae were repaired at six weeks of age and the palate will be repaired when the child is 18 months of age.

The following investigations were performed and were normal: serum urea, electrolytes, calcium, 

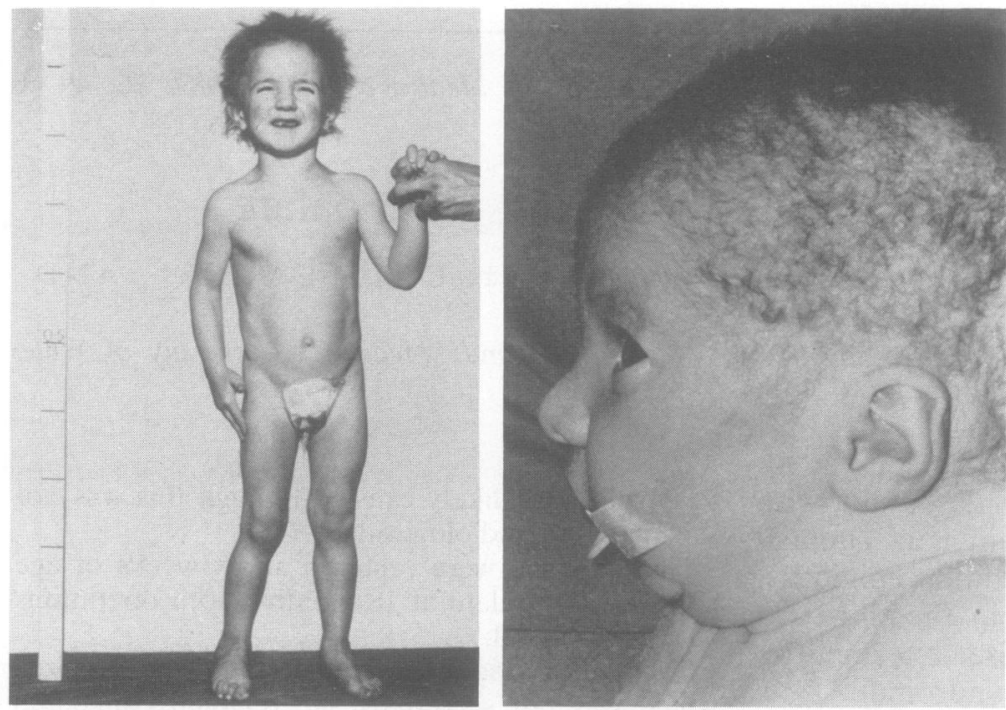

FIG 1 Left: the older sib at three and $a$ half years of age. Right: the younger sib at four weeks of age. Note spiky hair and retrognathia.

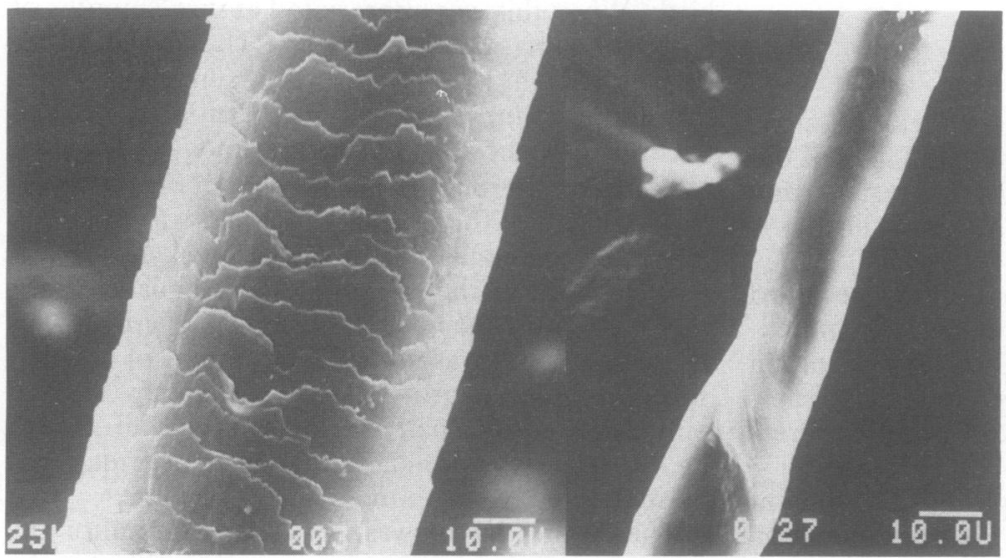

FIG 2 Electron micrograph of hair. Right: from older sib showing decreased shaft diameter, loss of scaling pattern, and pili torti. Left: normal hair for comparison.

phosphate, uric acid, amino acid chromatography, copper, caeruloplasmin, zinc, and liver function. Viral titres did not support congenital infection. The peripheral karyotype was normal male in both cases. Intracranial ultrasound and electroencephalogram were normal. A radiological skeletal survey in the first infant was normal. Scanning electron microscopy of hair strands showed a small shaft diameter, loss of scaling pattern, and pili torti. $X$ ray diffraction studies of the hair fibres showed normal elemental composition.

The parents are of normal stature and appearance. Their hair is of normal appearance and both parents have normal thyroid function. The mother has congenital right sided choanal atresia with a normal palate and epiglottis.
Discussion

Congenital hypothyroidism associated with choanal atresia, bifid epiglottis, and abnormal hair has notô been described before. Pabst et al reported twon brothers with congenital hypothyroidism and wispyn hair; however, these boys also had failure to thrive, recurrent chest infections, and hypohidrosis with decreased sweat glands. The skin was hyperpigmented and biopsy showed increased melanocytes? and mast cells. Non-specific abnormalities of tracheal cilia were reported. Hypothyroidism waso recognised at four years and six years of ageop respectively. Mental development was normal. Pike et $a l^{3}$ reported a similar syndrome in a girl who hade failure to thrive, hypohidrosis, and recurrent chest 
infections. Freckling of the trunk was conspicuous. Jejunal biopsy showed partial villus atrophy. Hypothyroidism was diagnosed at three and a half years of age and development was normal.

Zadic et $a l^{4}$ reported a girl who had hypothyroidism and sparse hair. In addition this patient also had facial dysmorphism (hypertelorism, depressed nasal bridge, and small mandible), oligodontia of both primary and secondary teeth, hypohidrosis, and an epibulbar dermoid cyst.

Patients with Johanson-Blizzard syndrome ${ }^{5}$ may have sparse hair and congenital hypothyroidism. These cases also have many other features, the most consistent of which are hypoplastic nasal alae, congenital cutis aplasia scalp defects, aplasia of the teeth, pancreatic exocrine deficiency, and sensorineural deafness.

Our cases differ from the previously reported cases of abnormal hair and hypothyroidism because they did not have failure to thrive or recurrent chest infections. Sweating and sweat pore counts were normal and significant facial dysmorphism was not a feature. The ultrastructural hair abnormalities were different from those described by Pabst et al $l^{2}$ (loss of scaling pattern and pili torti in addition to reduced fibre diameter). Upper airway anomalies in conjunction with congenital hypothyroidism has not been previously described. Hypothyroidism in our cases is probably the result of congenital athyroidia. It seems unlikely that this was the cause in other patients in view of the later presentation and normal mental development.
It is likely that this syndrome is genetically determined. The mode of inheritance is uncertain, but $\mathrm{X}$ linked recessive transmission with partial expression in the mother (in view of unilateral choanal atresia) and autosomal recessive inheritance must be considered.

These children were ascertained through a regional congenital hypothyroid screening programme, emphasising the importance of being aware of phenotypic as well as biochemical abnormalities. Further cases of this syndrome should be easier to ascertain through a hypothyroid screening programme.

\footnotetext{
References

1 Verbov J. Palmar ridge appearances in normal newborn infants and ridge appearance in relation to eccrine sweating. $\mathrm{Br} J$ Dermatol 1975;93:645-8.

2 Pabst HF, Garth O, McCoy EE. Hypohidrotic ectodermal dysplasia with hypothyroidism. J Pediatr 1981;98:223-7.

${ }^{3}$ Pike MG, Baraitser M, Dinwidie R, Atherton DJ. A distinctive type of hypohydrotic dysplasia featuring hypothyroidism. $J$ Pediatr 1986;108:109-11.

${ }^{4}$ Zadic Z, Barak Y, Levin S. Case report 112. Syndrome Identification 1983;(C4):24-7.

5 Johanson A, Blizzard R. A syndrome of congenital aplasia of the alae nasi, deafness, hypothyroidism, dwarfism, absent permanent teeth and malabsorption. J Pediatr 1971;79:982-7.
}

Correspondence and requests for reprints to $\mathrm{Dr} J \mathrm{~S}$ Bamforth, Department of Clinical Genetics, University of British Columbia, 4490 Oak Street, Vancouver, BC V6H 3V5, Canada.

\title{
Hydrocephalus, tall stature, joint laxity, and kyphoscoliosis: a new inherited disorder of connective tissue?
}

\author{
PETER DAISH*, MARTIN J HARDMAN*, AND MARGARET A LAMONT ${ }^{*}$ \\ ${ }^{*}$ Department of Paediatrics, St Mary's Hospital, Portsmouth; and †Department of Child Health, \\ Southampton General Hospital, Southampton.
}

SUMMARY We describe two sisters with hydrocephalus, tall stature, joint laxity, and thoracolumbar kyphosis.

\section{Case reports}

These two girls are the only children of healthy, unrelated, professionally qualified parents. The

Received for publication 2 Sepember 1987.

Revised version accepted for publication 7 March 1988 father, aged 34 years, is $185 \mathrm{~cm}$ tall $(+1 \cdot 6 \mathrm{SD})$. The mother, aged 30 years, is $162 \mathrm{~cm}$ in height (mean). Their head circumferences are within the normal ranges at $58 \mathrm{~cm}(+1.8 \mathrm{SD})$ and $56.5 \mathrm{~cm}(+1.5 \mathrm{SD})$ respectively.

The father was found on a routine medical examination at the age of 21 to have an aortic regurgitant murmur. He has remained asymptomatic and at present has no clinical signs. Recent cardiac ultrasound studies with Doppler colour flow mapping showed normal aortic root dimensions, 